\title{
Varicose veins in women with Pelvic Congestion Syndrome: the hypothesis of the hormonal pathogenesis
}

\author{
S Ricci ${ }^{1}$

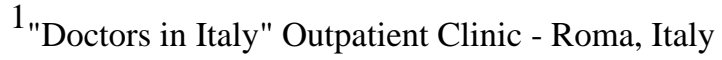

submitted: Dec 30, 2019, accepted: Oct 6, 2020, EPub Ahead of Print: Oct 20, 2020

Conflict of interest: None

DOI: 10.24019/jtavr.88 - Corresponding author:Prof. Stefano Ricci, varicci@tiscali.it

(C) 2018 Fondazione Vasculab impresa sociale ONLUS. All rights reserved.

\begin{abstract}
Pelvic veins incompetence may cause varicose veins formation in the lower extremity due to leak points of the pelvic circulation. This observation is particularly frequent in recurrence cases especially in multi parity. The cause of pelvic vein dilatation is still not clear. Traditional mechanism for varicose veins formation referred to leg varices cannot be transferred to pelvic circulation where a strong efficient pumping mechanism and a high hydrostatic column is missing. An alternative explanation is possible if hormonal factors are considered to contribute to vasodilatation (estrogen is a potent vasodilator), and pelvic veins are naturally exposed to high doses of ovarian hormones. Pelvic veins
\end{abstract}

\section{Leading idea}

Estrogens direct action on veins, i.e. vasodilation (variably mediated), could be the real cause of dilation of veins in pelvic veins incompetence possibly generating the Pelvic Congestion Syndrome ( PCS) and, in particular in pelvic derived lower extremity varicose veins.

\section{Introduction}

Lower extremity chronic venous insufficiency due to pelvic leak points in women has been described with an incidence of a $4 \%$ in 1976 by Hobbs $^{1}$ who examined 1000 women perivulvar varicosities.

Pelvic derived lower extremity varicose veins (primary or recurrent) result from pelvic venous hypertension that escapes to the legs through several points $^{2,3,4}$. The most common escape point is the perineal or $\mathrm{P}$ point, where the internal and external pudendal veins connect in the urogenital triangle. These leaking points dilatation/hypertension, rich in estrogens, may be directed through leak points to leg veins where estrogens effect of vasodilation is maintained. Then, at every Valsalva like action, some blood rich in estrogens passes in the leg network giving rise, among others, to perineal veins dilatation, recurrence after groin dissection for SFJ high ligation, intermittent leg pain/discomfort. Estrogens sampling studies could confirm this hypothesis and guide alternative treatments

Keywords Pelvic Congestion Syndrome, pelvic veins reflux, pelvic leak points, varices recurrence, estrogens action

can lead to inner thigh and posterior labial varicose veins. The next most common escape point is the inguinal or I point. At this location, pelvic venous plexus-derived reflux passes through the external inguinal ring via a recanalized vein of the round ligament, emerging in the groin medial to the common femoral vein. This can lead to groin and labial varicose veins ${ }^{5}$. Other less commonly discussed escape points include the gluteal $(\mathrm{G})$ points (inferior and superior) and varicose veins traveling along the sciatic nerve (O-obturator) and the Clitoris point ( $\mathrm{C}$ point), the anastomotic plexus between the bulbar vein and superficial dorsal clitoris vein. (reflux from Internal Pudendal vein into Anterior Saphena varicose vein through retrograde flow in bulbar vein, Plexus Ven. Communicans, Dorsal Clitoris Vein and External Pudendal) (Fig 1 and Table 1).

The recent UIP Consensus Document ${ }^{6}$ ignores completely this ultrasound based classification despite its practical validation and use by some of the same consensus Authors. 


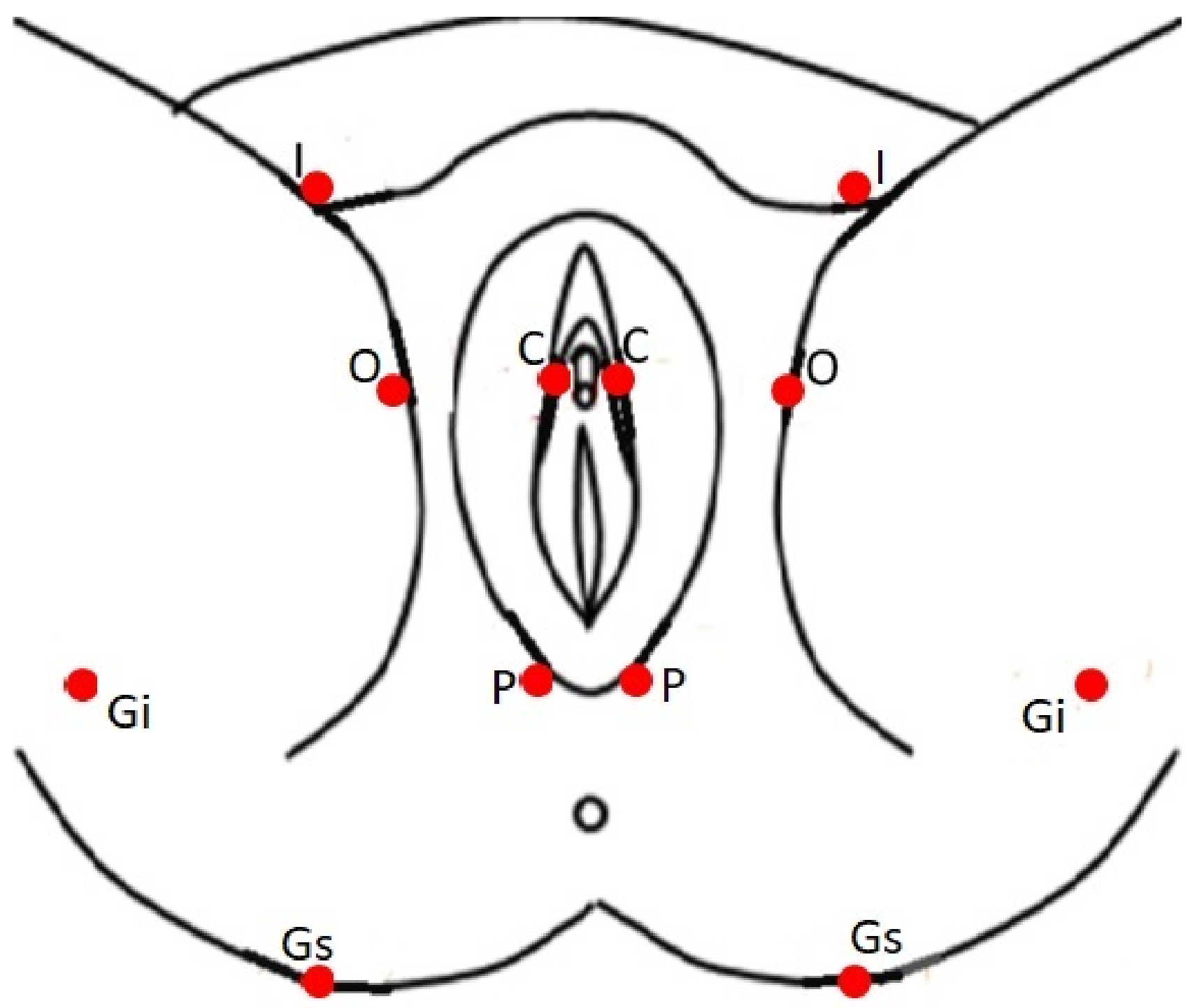

Fig 1 - Anatomical position of the most common escape points (6 each side): I - Inguinal point, $O$ - Obturator point, $C$ Clitoris point, P - Perineal point, Gs - Gluteal Superior point, Gi - Gluteal Inferior point.

Over 756 patients with varices fed by leaking points, Gianesini ${ }^{7}$ for example, found this incidence:

- Point P: 535 patients $(70.8 \%)$

- Point I: 156 patients $(20.7 \%)$

- Point GI: 28 patients (3.7\%)

- Point O: 24 patients $(3.2 \%)$

- Point GS: 13 patients (1.6\%)

(C point not cited)

Venous clinics that have used pelvic venography or transvaginal or transperineal duplex sonography to evaluate all patients with pelvic pain, Doppler ultrasound evidence of lower limb venous insufficiency, and evidence of pelvic venous origin have shown that $15 \%$ to $20 \%$ of patients have lower limb varicosities with a partial or complete pelvic origin $^{8}$.

The prevalence might be even higher in populations with persistent or recurrent varicose veins after previous treatment. Perrin reported a 17\% incidence of PCS in female patients with recurrence after surgical treatment of varicose veins ${ }^{9}$. However, the percentage of such patients can be as high as $30 \%{ }^{10}$. PCS was the source of non sapheno-femoral reflux in the groin in $6.1 \%$ of patients with primary varicose veins ${ }^{11}$. 


\begin{tabular}{|c|c|c|}
\hline Acronym & Name & Description \\
\hline $\mathrm{P}$ & Perineal point & $\begin{array}{l}\text { where the internal and external pudendal veins connect in } \\
\text { the urogenital triangle leading to inner thigh and posterior } \\
\text { labial varicose veins. (Alcot canal) }\end{array}$ \\
\hline I & Inguinal point & $\begin{array}{l}\text { reflux from pelvic venous plexus passes through the } \\
\text { external inguinal ring via a recanalized vein of the round } \\
\text { ligament, emerging in the groin medial to the common } \\
\text { femoral vein, leading to groin and labial varicose veins }\end{array}$ \\
\hline Gs & Gluteal Superior point & $\begin{array}{l}\text { upon the pyramidal muscle, connected to the Internal Iliac } \\
\text { Vein by the superior gluteal vein, gives mostly congenital } \\
\text { veins reflux and dilatation }\end{array}$ \\
\hline Gi & Gluteal Inferior point & $\begin{array}{l}\text { below the pyramidal muscle, connected to the Internal Iliac } \\
\text { Vein through the inferior Gluteal Vein, leads to varices } \\
\text { along the Sciatic Nerve }\end{array}$ \\
\hline $\mathrm{O}$ & Obturator point & $\begin{array}{l}\text { the Obturator Vein causes leg varices when draining in the } \\
\text { GSV instead of the Femoral Vein }\end{array}$ \\
\hline $\mathrm{C}$ & Clitoris point & $\begin{array}{l}\text { the anastomotic plexus between the bulbar vein and } \\
\text { superficial dorsal clitoris vein point }\end{array}$ \\
\hline
\end{tabular}

Table I - Pelvic escape points

Reflux from the pelvis or abdominal wall can also occur in $42 \%$ of patients with primary varicose veins associated with sapheno-femoral reflux and, in 35\% of those, reflux in the anterior accessory great saphenous vein 5 .

\section{Etiology of PCS}

The precise etiology of PCS is poorly understood. A reflux of blood in the pelvic and/or ovarian veins is the most evident occurence, due to the absence of functioning valves, resulting in retrograde blood flow and consequent venous dilatation. Valves are absent from the orifices of the gonadal veins in $15 \%$ of women, and, in those where valves are present, they are incompetent in $40 \%$ on the left and $35 \%$ on the right Usually the left ovarian vein is more (or initially) involved, possibly due to its anatomical (unfavorable) situation ${ }^{12}$.

However, in a group of 38 asymptomatic parous women who underwent computed tomographic (CT) scan imaging, Rozenblit et al. ${ }^{13}$ found an incidence rate of $47 \%$ of incompetent and dilated ovarian veins, suggesting that the symptoms of the pelvic venous disorders may be the result of factors other than gonadal venous insufficiency.

The cause of pelvic vein dilatation is still not clear. Traditional mechanism for varicose veins formation referred to leg varices ( diastolic reflux- systolic pumping emptying- high column hydrostatic pressure effect) cannot be transferred to pelvic circulation where a strong efficient pumping mechanism and a high hydrostatic column is missing.

\section{Estrogens contribution}

An alternative explanation is possible if hormonal factors are considered to contribute to vasodilatation, and pelvic veins are naturally exposed to high doses of ovarian hormones. Estrogen is a potent vasodilator. This effect occurs by various mechanisms, and estrogen receptors on human vascular cells are known to exist. Estrogen also causes nitric acid secretion, which causes relaxation of smooth muscle via stimulating nitric oxide synthase ${ }^{14}$. Nitric oxide not only dilates the uterine vessels, but also causes pelvic pain that can be blocked by nitric oxide inhibitors ${ }^{15}$.

During pregnancy estrogen level is very high contributing to the dilatation (60 times the initial volume) of the whole pelvic system. Moreover, dilated veins are more frequently observed with increased parity ${ }^{16}$. Partial recovery is described after delivery (6 months), while successive pregnancies tend to enhance dilatation and reduce recovery.

The ovarian veins are exposed to a 100 -fold high concentration of estradiol and estrone compared 
to the peripheral circulation. Resulting distension of the ovarian veins will worsen symptoms of $\mathrm{PCS}^{17}$. Reports of improvement in PCS symptoms when patients reach menopause or undergo hormonal suppression support this concept $^{18}$.

\section{Estrogens induced Angiogenesis related to recurrence}

Neovascularization refers to new blood vessel formation in the granulation tissue along the track of previously stripped or ligated veins. Even after correct functional ligation neovascularization has been reported to account for $25-94 \%$ of recurrent varicose veins and is the most common cause of recurrence, together with the development of varicose veins attributable to disease progression in many studies ${ }^{19}$.

It may be induced by diffusible angiogenic factors released from the surrounding tissues. Neovascularization may be part of the normal sequence of wound healing, originating from hypoxia induced activation of endothelial cells distal to the stump ligature leading to the release of angiogenic factors ${ }^{20}$.

Estrogens can be related to these factors:

In ovulating women, estrogens regulate of the processes of neovascular development in the uterus. This same process is essential in non reproductive tissue for wound healing, repair of damaged organs, restoration of blood supply to ischemic tissue and tumor growth. Estrogenic compounds increase proliferation of endothelial cells in vitro and in vivo in the vicinity of an endothelial lesion, involved in maintaining and repairing damaged vascular lining, in angiogenesis to ischemic tissue, and in the formation of new blood vessels or vasculogenesis ${ }^{14}$.

This specific effect could explain the particular tendency to groin recurrence (neovascularization) after junction ligation procedures when pelvic varices are involved. Also new varicose veins appearance due to pelvic veins in areas other than GSV could be concerned in the same way ${ }^{21}$.

\section{Estrogens centered Pathophysiology}

If the pelvic system become and remain partially dilated ovarian veins (and connected network) directly receiving estrogens from ovaries, are submitted to some degree stasis where estrogens contact time is prolonged. In subjects congenitally predisposed (increased expression of venous tissue estrogen receptors) pelvic veins are then submitted constantly to the same direct effect of vasodilatation, possibly causing pain and discomfort (Pelvic Pain Syndrome- Pelvic Congestion Syndrome).
Pelvic veins dilatation, rich in estrogens, may be directed through leak points to leg veins where estrogens effect of vasodilation is maintained. Then, at every Valsalva like action, some blood rich in estrogens passes in the leg network possibly causing:

- Perineal veins dilatation, with typical aspect "in rosary" due to extreme dilation in very thin vessels ${ }^{1}$

- Saphenous dilatation with reflux without terminal valve incompetence ${ }^{1}$.

- Recurrence after groin dissection for SFJ high ligation, (presence of multiple small tortuous veins in anatomic proximity to a previous intervention

- Limited groin recurrence in Junction sparing methods (endovascular chemical/heat-surgical)

- Recurrent varices of the entire limb not justified by traditional feeding points.

- Intermittent leg pain/discomfort

- Symptoms amelioration after menopause

- Symptoms amelioration with compression hosiery

\section{Conclusions}

Pelvic veins dilatation and consequent incompetence may induce, through leaking points, varices of the legs in $15 \%$ to $20 \%$ of female patients with this condition. These varices seem to recur after surgical treatments more often than junction incompetence varicose veins ${ }^{9}$. Lower extremity varicose veins due to pelvic leak points cannot be induced by the same mechanism of junction incompetence varices, whose dilatation is referred to long standing hydrostatic pressure effect during muscular pumps diastole. Although valvular incompetence is similar, in the pelvic network an active pump is missing and hydrostatic pressures are low, provided that no obstruction is present. At the opposite, in pelvic network high estrogen concentration is present, and when dilatation is established venous stasis and long lasting contact with ovarian products is the result. The well studied rapid vasodilation effect of estrogens on veins could be the alternative explanation of PCS and, in particular, of related leg varices ${ }^{14}$. Neoangiogenesis could be enhanced by ormones concentration in operated areas. Estrogens sampling studies could confirm this hypothesis and guide alternative treatments. The next step of this research will be the proposal of a multi center study with the porpose of measuring hormons and mediators levels according to Asciutto research ${ }^{22}$.

This Author found hormone levels to be higher in the lower limb than in the upper limb only in patients where PCS was associated with varicose veins. Blood samples were collected after venous duplex ultrasound imaging and diagnosis of GSV incompetence leading to varicose veins. The GSV was marked with the help of US at the groin or the proximal part of the medial thigh. Blood samples were 
collected as near to the SFJ as possible using a 23-gauge needle with the patients in upright position and performing a Valsalva manoeuvre. In the upper limb, blood was taken from an ante-cubital vein.

Furthermore, Osvald ${ }^{23}$ assessed hormone levels of varicose veins to detect the incompetence of the $\mathrm{OV}$ as a source of varices in the symptomatic group finding that the concentration level of oestradiol in the sample from painful varicose veins was two to nine times higher compared with samples from the non-affected leg and brachial vein.

If hormones blood samples importance could be confirmed, apart from costs lowering due to limiting more invasive researches, it would be possible also to:

\section{References}

1) Hobbs JT. Varicose veins arising from the pelvis due to ovarian vein incompetence Int J Clin Pract, October 2005, 59, 10, 11951203

2) Franceschi C, Bahnini A. Treatment of lower extremity venous insufficiency due to pelvic leak points in women. Ann Vasc Surg 2005Mar;19(2): 284-8

3) Franceschi C. Anatomie fonctionnelle et diagnostic des points de fuite bulboclitoridiens chez la femme (point C). J Mal Vasc. 2008;33:42.

4) Zamboni P, Mendoza E, Gianesini S. General Considerations to the Treatment of Pelvic Leak Points, Ch. 8 in: Saphenous VeinSparing Strategies in ChronicVenous Disease. Springer International Publishing AG, Cham, Switzerland

5) Monedero JL, Ezpeleta SZ, Castro JC, Ortiz MC, Fernandez GS. Embolization treatment of recurrent varices of pelvic origin. Phlebology. 2006;21:3-11

6) Pier-Luigi ANTIGNANI et al. Diagnosis and treatment of pelvic congestion syndrome: UIP consensus document. International Angiology 2019 August;38(4):265-83.

7) Gianesini S, Antignani PL,Tessari L . Pelvic congestion syndrome: does one name fit all? Phlebolymphology- 2016; 23(3) :142-145

8) Marsh P, Holdsock J, Harrison C, SmithPrice BA, Whiteley MS. Pelvic vein reflux in female patients with varicose veins: comparison of incidence betweena specialist private vein clinic and the vascular department of a National Health Service District General Hospital. Phlebology. 2009;24(3):108-.

9) Perrin MR, Labropoulos N, Leon LR Jr. Presentation of the patient with recurrent varices after surgery (REVAS). J Vasc Surg. 2006;43:327-334.

10) Jiang P, van Rij AM, Christie RA, Hill GB, Thomson IA. Non-saphenofemoral venous reflux in the groin inpatients with varicose veins. Eur JVasc Endovasc Surg 2001;21:550-7.

11) García-Gimeno $\mathrm{M}$, Rodríguez-Camarero $\mathrm{S}$, TagarroVillalba S, Ramalle-Gomara E, González-González E, Arranz MA, et al. Duplex mapping of 2036 primary varicose veins. J Vasc Surg2009;49:681-9.
- State which cases are at risk of recurrence. A grading in two or more clinical group could/should be created - Verify the effect and duration of treatment by monitoring hormones level

- Limit aggressive procedure or, at the opposite, indicate further treatment

- Find chemical antagonist to local estrogens and mediators effects

- Develop some kind of conservative treatments (compression pants limiting leaking flow) ${ }^{24}$

- Analyze possible temporary ovary functional block, limited , for example, to post-operative period

Based on this premise, a further paper will be issued later on proposing a specific reserch on hormonal sampling to centres involved in PCS.

12) Asciutto Pelvic vein incompetence: a review of diagnosis and treatment. Phlebolymphology. 2012 ; 19 (2): 84-90

13) Rozenblit AM, Ricci ZJ, Tuvia J, Amis ES Jr. Incompetent and dilated ovarian veins: a common finding in asymptomatic parous women. Am J Radiol 2001;176:119-22.

14) Miller VM , Duckles SP Vascular Actions of Estrogens: Functional Implications Pharmacol Rev 60:210-241, 2008)

15) Kurt A .The relation between pelvic varicose veins, chronic pelvic pain, and lower extremity venous insufficiency in women. Phlebolymphology. 2008; 15 (2): 61-67

16) Hodgkinson CP. Physiology of the ovarian veins during pregnancy. Obstet Gynecol. 1953;1:26-37.

17) Stones RW. Pelvic vascular congestion - half a century later. Clin Obstet Gynecol. 2003;46:831-6.

18) Venbrux A.C., Sharma G.K., Jackson E.T., Harper A.P., Hover L. (2012) Pelvic Varices Embolization.pp 37.59. In: Ignacio E., Venbrux A. (eds) Women's Health in Interventional Radiology. Springer, New York, NY.

19) Wittens C. et Al Management of Chronic Venous Desease Clinical Practice Guidelines of the European Society for Vascular Surgery (ESVS). EJVES49(6):678-737

20) Witmer AN, van Blijswijk BC, Dai J, Hofman P, Partanen TA, Vrensen GF, et al. VEGFR-3 in adult angiogenesis. J Pathol 2001;195:490-7.

21 ) Brake M, Lim CS, Shepherd AC, Shalhoub J, , and Davies $\mathrm{AH}, \mathrm{DM}$, Pathogenesis and etiology of recurrent varicose veins. J Vasc Surg 2013;57:860-8.

22) Asciutto G, Mumme A, Asciutto KC, B. Geier Br Oestradiol Levels in Varicose Vein Blood of Patients with and without Pelvic Vein Incompetence (PVI): Diagnostic Implications. Eu J VascEndovascSurg (2010) 40, 117e121.

23) Oswald M, Heintz C,Wolhlaib U. How to prove incompetence of the ovarian vein as a source of varicogenesis by testing the hormone content of the varicose veins of the leg. In: Phlebolymphology. Special issue for European Congress of UIP, Bremen; 1999. 
24) Gavrilov SG, Karalkin AV and Turischeva OO. Compression treatment of pelvic congestion syndrome. Phlebology3(6):418-424. 